\title{
Detection of Melanoma Nodal Metastases; Differences in Detection Between Elderly and Younger Patients Do Not Affect Survival
}

\author{
S. Kruijff, MD ${ }^{1}$, E. Bastiaannet, MSc $^{1}$, A. J. H. Suurmeijer, MD, PhD $^{2}$, and H. J. Hoekstra, MD, PhD ${ }^{1}$ \\ ${ }^{1}$ Surgical Oncology, University Medical Centre Groningen, University of Groningen, Groningen, The Netherlands; \\ ${ }^{2}$ Pathology, University Medical Centre Groningen, University of Groningen, Groningen, The Netherlands
}

\begin{abstract}
Background. Melanoma lymph nodes metastases may be detected by patients or by physicians. Understanding the outcomes of self-detection or physician detection is essential for the design of follow-up studies. We evaluated the role of the method of detection in nodal disease in the prognosis of melanoma patients who underwent therapeutic lymph node dissection (TLND).

Materials and Methods. All melanoma patients with palpable lymph nodes were included in a prospective database $(n=98)$, and the method of detection was recorded. Detection of lymph node metastases compared with pathological findings in the TLND was assessed by multivariate logistic regression. Disease-free survival (DFS) and disease-specific survival (DSS) were assessed by univariate and multivariate Cox proportional hazard analysis.

Results. Nodal metastases were detected by physicians in $45 \%$ and by patients in $55 \%(P<0.001)$. Age was significantly associated with method of detection. Patients $\leq 60$ years detected $69 \%$ their lymph node metastases as opposed to $32 \%$ of patients $>60$ years (odds ratio [OR] 0.3; $P=0.007)$. However, this was not associated with prognostic findings in TLND, number of positive nodes, tumor size, or extranodal spread. Method of detection or age at the time of nodal metastases was not significantly associated with 2-year DFS or DSS.

Conclusions. $45 \%$ of all lymph node metastases in stage I-II melanoma patients are physician detected. Younger
\end{abstract}

(C) The Author(s) 2010. This article is published with open access

at Springerlink.com

First Received: 3 December 2009;

Published Online: 5 May 2010

S. Kruijff, MD

e-mail: skruyff@hotmail.com patients detect their own lymph node metastases significantly more often than elderly patients. However, neither the method of detection nor age correlates with DSS. More frequent follow-up would not alter DFS and DSS significantly.

The incidence of melanoma is increasing worldwide. In the Netherlands, the incidence increased from 9.5 to 13.7 per 100,000 in men and from 13.4 to 18.5 per 100,000 in women between 1989 and 2003. Approximately 90\% of patients have stage I or II melanoma at diagnosis, and the incidence of patients with a thin melanoma has increased. ${ }^{1-5}$ Although the early diagnosis of cutaneous melanoma with small Breslow's tumor thickness has been responsible for the leveling off of overall melanoma mortality, the incidence at the same time has continued to rise. ${ }^{6}$ The number of melanoma patients requiring follow-up surveillance has doubled in the Netherlands. ${ }^{1}$ Despite improved public awareness and earlier diagnosis and treatment, mortality from melanoma increased from 2.5 to $3.6 / 100,000$ in men and from 2.0 to $2.4 / 100,000$ in women in the Netherlands between 1989 and $2003 .{ }^{1}$

Several studies have been performed concerning survival in patient-detected versus physician-detected recurrences. Because most of first melanoma recurrences are detected by patients or their partners, the value of high-frequency follow-up has often been questioned. ${ }^{7,8}$ Over half of patients $(55 \%)$ with early-stage melanoma detect their own recurrence(s).$^{9-20}$ In recent decades, several follow-up schedules have been suggested with large variations and without international consensus. ${ }^{3}$ Proposals for these schedules are based on risk calculations concerning melanoma recurrence and cost effectiveness. Several authors have recommended a reduction in the intensity of follow-up regimens based on these factors. $^{9-11,21}$ Others claim that a more intensive 


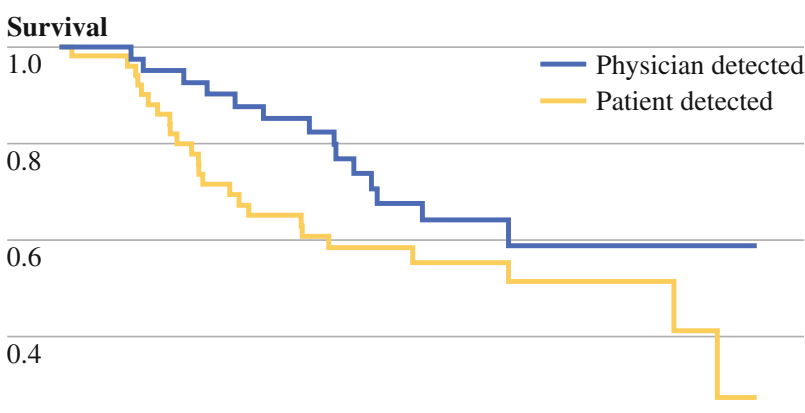

0.2

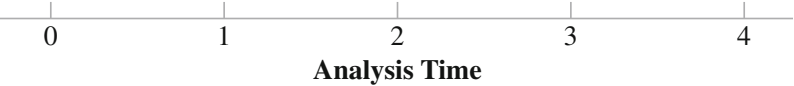

FIG. 1 Kaplan-Meier curve DSS melanoma patients with positive lymph nodes detected by physician versus detected by patient

follow-up will improve outcome because of earlier detection. $^{12,22,23}$

Of the various follow-up methods performed by physicians, only medical history and physical examination seem to be cost effective. ${ }^{20}$ Despite these findings, most melanoma patients are still followed up on a frequent basis, mostly for education, reassurance, or inclusion in clinical trials.

Studies concerning the method of nodal metastasis detection have not shown a difference in survival comparing physician-detected versus patient-detected recurrences. Intense follow-up does not seem to contribute to disease-free interval or overall survival, as physiciandetected lesions do not have a better prognosis than those detected by patients themselves. ${ }^{3,16}$

Patients with clinical stage IIIb melanoma (palpable lymph node metastases) have a 5-year survival of 59\%. ${ }^{24} \mathrm{~A}$ better understanding of the method of detection of palpable melanoma metastases (i.e., by patient or physician) and its influence on survival is essential to resolve the aforementioned follow-up controversy.

The aim of this study was to evaluate the role of the method of detection, by patient or physician, in melanoma patients with palpable lymph nodes and to analyze the association with pathological findings in therapeutic lymph node dissection (TLND) and the impact of the detection method on disease-free and disease-specific survival. The method of detection of positive nodes (patient versus physician) might not only have impact on survival but might also influence the number of positive nodes, the tumor size, or the presence of extranodal growth in the TLND.

\section{MATERIALS AND METHODS}

Patients with primary melanoma were treated with wide local resection ( 1 or $2 \mathrm{~cm}$ ) with or without sentinel lymph node biopsy and, if indicated, therapeutic lymph node
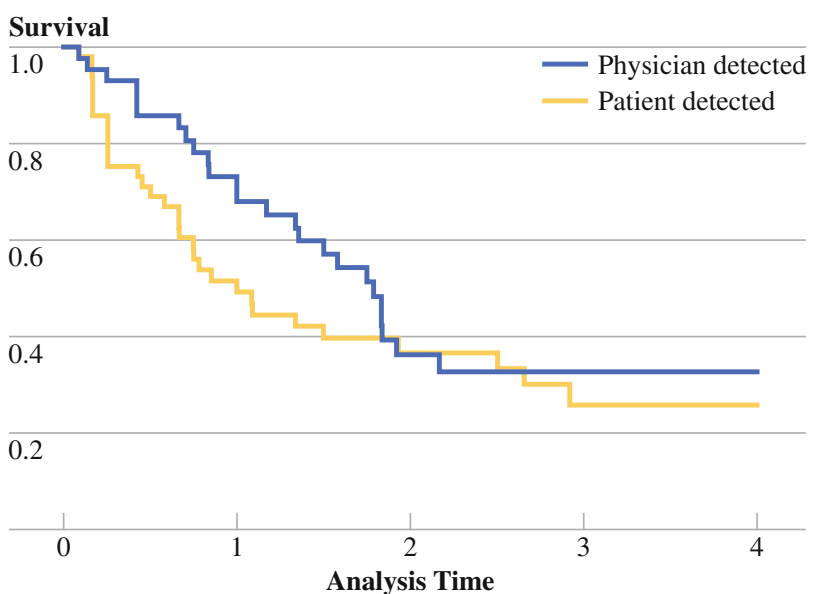

FIG. 2 Kaplan-Meier curve DFS melanoma patients with positive lymph nodes detected by physician versus detected by patient

dissection. Stage I and II melanoma patients were followed after treatment in accordance with the Dutch National Guideline Treatment of Melanoma (www.oncoline.nl). Postoperative follow-up included physical examination every 3 months for the first year, every 4 months for the second year, and every 6 months thereafter. Standard radiographic or serum investigations were not performed.

All patients with clinically and cytologically proven lymph node metastases of melanoma (AJCC stage IIIb) were included in this study. If palpable positive nodes were found during regular follow-up, this was recorded as "physiciandetected nodal metastases." When positive palpable nodes were recorded after a patient-initiated visit, this was recorded as "patient-detected nodal metastases." Patients without distant metastases on fluorodeoxyglucose-positron emission tomography (FDG-PET) and computed tomography (CT) received a TLND with curative intent and were entered into a single prospective institutional database. The stage IV upstaged patients were referred for further palliative treatment to their primary physician, medical oncologist, or radiation oncologist and excluded for further follow-up. Patients who presented with local recurrence or in-transit disease were not included.

Patients with nodal metastases of $\geq 3 \mathrm{~cm}$ and/or $\geq 3$ positive lymph nodes and/or extranodal (EN) disease received adjuvant radiotherapy $(20 \times 2.4 \mathrm{~Gy})$. Data examined include patient demographics, clinical and histopathologic characteristics of the tumor, date and type of operation, site and date of first (nodal) and second recurrence, method of detection of recurrence (i.e., patient or physician during standard follow-up), and status at last follow-up.

The study was approved by the Medical Ethical Committee of the University Medical Centre Groningen (UMCG). 


\section{Statistics}

For retrospective analysis, patients were divided by age ( $\leq 60$ versus $>60$ years of age). Factors associated with method of detection were analyzed by univariate and multivariate logistic regression analysis. Four subgroups were generated based on the combinations of young versus elderly and physician versus patient detection to assess for associations with pathological variables. Factors associated with disease-free survival (DFS) and disease-specific survival (DSS) were assessed by univariate and multivariate Cox proportional hazard analysis. For DFS, any recurrence was recorded as an event; for DSS, death resulting from melanoma was considered an event. Follow-up was truncated at 4 years.

\section{RESULTS}

\section{Patients}

In the period 2003-2008, 98 patients [54 males $(55.1 \%)$ and 44 females $(44.9 \%$ ), median age 57.7 years (range 28.5-86.7)] with stage IIIb melanoma, based on PET and spiral CT, underwent a TLND (Table 1). Median time from primary melanoma treatment to nodal recurrence or nodal recurrence of an unknown primary melanoma was 22.0 (0315.3) months.

\section{Detection}

Physicians detected $45 \%$ of the nodal metastases and patients detected $55 \%(P=0.001$; Table 2$)$. Of the 61 patients in the younger age group ( $\leq 60$ years), 19 nodal metastases were physician detected (31\%) whereas 42 nodal metastases were patient detected (69\%). Of the 37 elderly patients ( $>60$ years), 12 nodal metastases were patient detected $(32 \%)$ and 25 nodal metastases physician detected $(68 \% ; P=0.001)$.

Table 2 also shows the results of univariate and multivariate logistic regression analysis of the association between method of detection and pathological information from the lymph node dissection, sex, age, and nodalbearing area (axilla, groin, neck). Age was significantly associated with method of detection: $69 \%$ of patients $\leq 60$ years detected their nodal metastases versus $32 \%$ of the patients $>60$ years (odds ratio [OR] $0.3 ; P=0.007$ in multivariate analysis).

Patients with a thin primary melanoma had a higher ratio of patient-detected positive lymph nodes $(P=0.05)$. This was, however, not statistically significant in multivariate analysis.

Sex, regional nodal basin site, number of nodes removed, number of positive nodes, tumor size, and
TABLE 1 Patient and tumor characteristics of 98 patients with clinically and cytological proven lymph node metastases of melanoma (AJCC stage IIIb)

\begin{tabular}{|c|c|c|}
\hline & Number & Percentage \\
\hline \multicolumn{3}{|l|}{ Sex } \\
\hline Male & 54 & 55.1 \\
\hline Female & 44 & 44.9 \\
\hline \multicolumn{3}{|l|}{ Age (years) } \\
\hline$\leq 60$ & 61 & 62.2 \\
\hline$>60$ & 37 & 37.8 \\
\hline \multicolumn{3}{|l|}{ Primary melanoma } \\
\hline \multicolumn{3}{|l|}{ Localization } \\
\hline Upper extremities & 11 & 11.2 \\
\hline Head and neck & 8 & 8.2 \\
\hline Lower extremities & 39 & 39.8 \\
\hline Trunk & 34 & 34.7 \\
\hline Unknown primary & 6 & 6.1 \\
\hline \multicolumn{3}{|l|}{ Breslow thickness } \\
\hline$\leq 2.0$ & 43 & 43.9 \\
\hline$>2.0$ & 49 & 50.0 \\
\hline Unknown & 6 & 6.1 \\
\hline \multicolumn{3}{|l|}{ Clark level } \\
\hline I-III & 33 & 33.7 \\
\hline IV-VI & 59 & 60.2 \\
\hline Unknown & 6 & 6.1 \\
\hline \multicolumn{3}{|l|}{ Ulceration } \\
\hline Yes & 22 & 22.5 \\
\hline No & 76 & 77.5 \\
\hline \multicolumn{3}{|c|}{ Lymph node metastases } \\
\hline \multicolumn{3}{|c|}{ Lymph node dissection } \\
\hline Axilla & 34 & 34.7 \\
\hline Groin & 50 & 51.0 \\
\hline Neck & 14 & 14.3 \\
\hline \multicolumn{3}{|c|}{ Number of nodes removed } \\
\hline$<15$ & 48 & 49.0 \\
\hline 15 or more & 50 & 51.0 \\
\hline \multicolumn{3}{|l|}{ No. of positive nodes } \\
\hline 2 or less & 53 & 54.1 \\
\hline$>2$ & 45 & 45.9 \\
\hline \multicolumn{3}{|l|}{ Tumor size $(\mathrm{cm})$} \\
\hline$\leq 3.0$ & 62 & 63.3 \\
\hline$>3.0$ & 36 & 36.7 \\
\hline \multicolumn{3}{|l|}{ Extranodal growth } \\
\hline Yes & 27 & 27.5 \\
\hline No & 71 & 72.5 \\
\hline
\end{tabular}

extranodal growth were not associated with method of detection in multivariate analysis.

There were no significant differences in pathological findings when the groups were divided in 4 groups: patient-detected younger age ( $\leq 60$ years), patient-detected 
TABLE 2 Detection of lymph node metastases in association with pathological results of lymph node dissection
Overall: $44.9 \%$ detected by physician and $55.1 \%$ by patients $(P<0.001)$

\begin{tabular}{|c|c|c|c|c|c|}
\hline & \multirow[t]{2}{*}{ Patient-detected (\%) } & \multicolumn{2}{|c|}{ Univariate analysis } & \multicolumn{2}{|c|}{ Multivariate analysis } \\
\hline & & OR $(95 \% \mathrm{CI})$ & $P$ value & OR $(95 \% \mathrm{CI})$ & $P$ value \\
\hline Sex & & & 0.13 & & 0.20 \\
\hline Male & 48.2 & 1.0 & & 1.0 & \\
\hline Female & 63.6 & $1.9(0.8-4.3)$ & & $1.8(0.7-4.6)$ & \\
\hline Age & & & 0.001 & & 0.007 \\
\hline$\leq 60$ & 68.9 & 1.0 & & 1.0 & \\
\hline$>60$ & 32.4 & 0.2 & & $0.3(0.1-0.7)$ & \\
\hline Breslow thickness & & & 0.05 & & 0.22 \\
\hline$\leq 2.0$ & 67.4 & 1.0 & & 1.0 & \\
\hline$>2.0$ & 42.9 & $0.4(0.2-0.8)$ & & $0.5(0.2-1.3)$ & \\
\hline Unknown primary & 66.7 & $0.9(0.2-5.9)$ & & $2.1(0.3-15)$ & \\
\hline Lymph node region & & & 0.56 & & \\
\hline Axilla & 61.8 & 1.0 & & & \\
\hline Groin & 50.0 & $0.6(0.3-1.5)$ & & & \\
\hline Neck & 57.1 & $0.8(0.2-2.9)$ & & & \\
\hline Nodes removed & & & 0.53 & & \\
\hline$<15$ & 58.3 & 1.0 & & & \\
\hline$\geq 15$ & 52.0 & $0.7(0.3-1.7)$ & & & \\
\hline \multicolumn{6}{|l|}{ Positive nodes } \\
\hline$\leq 2$ & 47.2 & 1.0 & 0.09 & 1.0 & 0.17 \\
\hline$>2$ & 64.4 & $2.0(0.9-4.6)$ & & $1.9(0.7-4.9)$ & \\
\hline Tumor size $(\mathrm{cm})$ & & $1.2(0.9-1.6)$ & 0.09 & $1.2(0.9-1.6)$ & 0.17 \\
\hline \multicolumn{6}{|l|}{ Extranodal growth } \\
\hline Yes & 66.7 & 1.0 & 0.16 & 1.0 & 0.48 \\
\hline No & 50.7 & $0.5(0.2-1.3)$ & & $0.7(0.2-2.0)$ & \\
\hline
\end{tabular}

when compared with detection by patients, no significant difference could be found (Figs. 1, 2).

\section{DISCUSSION}

\section{Survival}

Multivariate analysis showed no significant difference in 2-year DFS for physician-detected versus patient-detected nodal recurrences (Table 3). Univariate analyses showed that DFS was associated with the lymph node bearing area, the number of positive nodes, node size, and extranodal growth pattern.

The 2-year DSS in males (53\%) was significantly shorter than that in females $(75 \%$; HR $0.3 ; P=0.004)$. DSS was significantly reduced in patients with $\geq 2$ positive nodes $(51 \%)$ compared with patients with $<2$ positive nodes (72\%; hazard ratio [HR] $2.2 ; P=0.03)$. Multivariate analysis showed no significant differences for DSS related to age, Breslow thickness, ulceration, lymph node bearing area (axilla, groin, neck), number of removed nodes $(\leq 15$ or $>15$ nodes), tumor size $(\leq 3$ or $>3 \mathrm{~cm}$ ), or extranodal growth (Table 3). Although in univariate analysis a trend in DSS was noted $(P=0.08)$ in favor of the physician-detected group, in multivariate analysis,
The most efficacious follow-up scheme for melanoma patients is uncertain. Understanding the impact of the method of detection of nodal recurrence on prognosis is important in determining the most appropriate follow-up. Despite controversy about follow-up in melanoma, our results show that nodal metastases are still detected by physicians in almost $45 \%$ of the patients. Young patients detect their own lymph node metastases significantly more often than older patients $(68 \%$ vs. $32 \%)(P=0.007)$. However, in patients undergoing close clinical surveillance neither the method of detection (patient versus physician) nor age seems to have a significant influence on 2-year DSS or DFS. Furthermore, no correlation could be found between the methods of detection and the number of positive nodes, lymph node size, or extranodal growth.

Despite this encouraging percentage of almost $45 \%$ detected nodes by physicians, this rate does not seem to result in any survival advantage. Earlier follow-up studies describe an increasing controversy about the efficacy of an 
TABLE 3 Disease-specific survival (DSS) and disease-free survival (DFS) in melanoma patients AJCC stage IIIb in correlation to detection by physician versus detection by patient

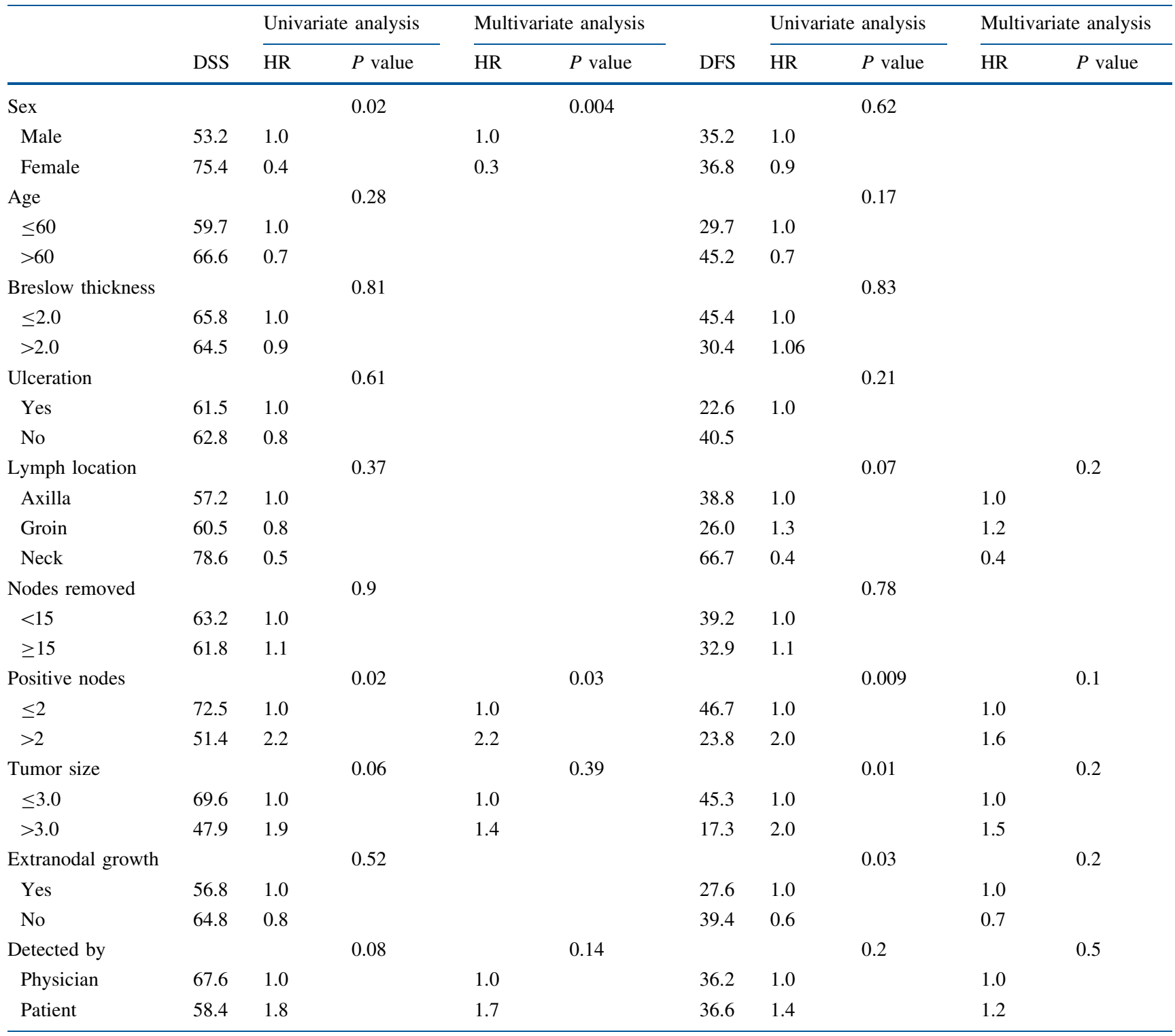

intensive follow-up scheme for melanoma patients as is still organized in a lot of hospitals today.

This is the first study evaluating the method of detection of nodal recurrence in stage IIIb melanoma and the impact of patient- or physician-detected nodal metastases on survival.

Patients with clinical stage IIIb melanoma (palpable lymph node metastases) have a 5-year survival of $59 \% .^{24}$ The most well-recognized causes for this low survival rate is the variation in the number of positive nodes, tumor size, and presence of extranodal growth.

Another cause for low survival rates in this patient category might be understaging. Bastiaannet et al. revealed that staging with FDG-PET of clinically stage IIIb patients resulted in upstaging of $22 \%$ to stage IV. In $19 \%$ treatment was changed, usually from surgery to systemic treatment. ${ }^{25}$ Patients in our current study were all staged with FDG-PET and CT and therefore can be considered as "true" AJCC stage IIIb patients.

Survival might also be influenced by follow-up and method of detection. We expected physician-detected positive lymph node status to correlate with a lower number of positive nodes, smaller tumor size, and absence of extranodal growth in the TLND. This association was not found despite a positive trend in DSS $(P=0.08)$ in the advantage of physician-detected nodes (Table 3 ).

Follow-up of melanoma has different purposes: to detect first melanoma recurrence, to assess treatment efficacy, and to detect a second primary melanoma $(2-6 \%) .^{26-28}$ Also of great importance are patient reassurance and 
documentation or inclusion for clinical trials. Follow-up schemes are often of high intensity; however, resources in many centers are insufficient to deal with the increasing patient load. Therefore, identifying and integrating evidence concerning the efficacy of follow-up strategies is important.

In 2003 Garbe et al. performed a prospective follow-up study in melanoma patients following an intensive followup scheme (every 3 months for the first 5 years and every 6 months during the 6 th to 10 th years). ${ }^{12}$ The authors claimed that $83 \%$ of all recurrences were detected by a physical examination during regular follow-up, and only $17 \%$ were detected by patients themselves. However, various AJCC melanoma stages were included in this study. Francken et al. performed a large retrospective study and found that only $62 \%$ of all types of recurrences were identified by patients themselves; however, three-quarters of first melanoma recurrences (FMR) were detected by patients or their partners, of which $11 \%$ were found by selfexamination. ${ }^{3}$ In the present study, no significant survival difference was found comparing patient-detected versus physician-detected nodal metastasis.

Additionally, patient age did not seem to have a significant influence on 2-year DSS or DFS. In patients older than 60 years, almost $70 \%$ of the detected nodes were found by a physician; in contrast, patients at or below 60 years of age detected their own nodes $70 \%$ of the time. Earlier literature reports age as an independent prognostic factor, perhaps presenting a surrogate for declining host defense mechanism associated with advancing age. ${ }^{2}$ Numerous studies have demonstrated that older patients have a lower survival rate, especially those over 60 years of age. ${ }^{29-34}$ The older patient might not detect positive lymph nodes because of a certain physical negligence that occurs with aging. However, our results surprisingly did not identify any survival disadvantage associated with delayed detection of nodal metastases. This might be explained by a small patient population or a follow-up period that is too short. Another explanation could be related to the recent report by Conway et al., who found that lymphatic function declines with age. ${ }^{35}$ Hypothetically, in older patients, declining lymphatic function might modify metastatic patterns and slow the process of dissemination.

Overall, it can be concluded that no study to date has proven any disease-free survival or overall survival benefit related to intense follow-up surveillance as there are no prospective studies that compare high-frequency to no or low-frequency follow up.

With the frequency of follow-up that was used in this study, the DFS and DSS for patients capable themselves of detecting a palpable node in the regional nodal basin and those unable to do so, were not significantly different.
Otherwise stated, it could be concluded that the above frequency of follow-up is sufficiently close for the detection and treatment of nodal disease. More frequent followup probably would not alter the DFS and DSS significantly. Therefore, arguments for more frequent follow-up than the aforementioned scheme are hard to justify as physiciandetected lesions do not have a better prognosis than those detected by patients. $3,7,8$ Whether follow-up with sparser intervals could be designed in a responsible way cannot be answered by this study.

Prospective, randomized, high-quality methodological research is required in order to develop meaningful applicable guidelines. Currently, no international consensus has been reached concerning the optimal frequency of followup visits for melanoma patients. Follow-up should be based on individual patient characteristics; multiple patient factors should be used to design the most appropriate followup. $^{36}$ A clinical randomized trial (MELFO) is currently underway at the University Medical Centre Groningen to evaluate the safety and cost effectiveness of reduced follow-up surveillance. ${ }^{37}$ In this RCT a high-frequency follow-up scheme will be compared with a less-frequent and better differentiated follow-up scheme adjusted to melanoma AJCC stage.

In conclusion, more than $55 \%$ of lymph node metastases in melanoma are detected by the patient. Younger patients detect their own lymph node metastases significantly more often than elderly patients without any impact on DSS and DFS. The data of our study will add to the controversy about the value of high-frequency follow-up regimens in melanoma. Prospective, randomized, high-quality methodological research has been started to develop meaningful applicable guidelines (MELFO).

OPEN ACCESS This article is distributed under the terms of the Creative Commons Attribution Noncommercial License which permits any noncommercial use, distribution, and reproduction in any medium, provided the original author(s) and source are credited.

\section{REFERENCES}

1. htpp://www.ikcnet.nl.

2. Balch CM, Buzaid AC, Soong SJ, Atkins MB, Cascinelli N, Coit DG, et al. Final version of the American Joint Committee on Cancer staging system for cutaneous melanoma. J Clin Oncol. 2001;19:3635-48.

3. Francken AB, Bastiaannet E, Hoekstra HJ. Follow-up in patients with localised primary cutaneous melanoma. Lancet Oncol. 2005;6:608-21.

4. de Vries E, Bray FI, Coebergh JW, Parkin DM. Changing epidemiology of malignant cutaneous melanoma in Europe 19531997: rising trends in incidence and mortality but recent stabilizations in western Europe and decreases in Scandinavia. Int $J$ Cancer. 2003;107:119-26.

5. Goldsmith LA, Askin FB, Chang AE, Cohen C, Dutcher MD, Gilgor RS, et al. Diagnosis and treatment of early melanoma: 
NIH consensus development panel on early melanoma. JAMA. 1992;268:1314-9.

6. Garbe C, Eigentler TK. Diagnosis and treatment of cutaneous melanoma: state of the art 2006. Melanoma Res. 2007;17:117-27.

7. Francken AB, Shaw HM, Accortt NA, Soong SJ, Hoekstra HJ, Thompson JF. Detection of first relapse in cutaneous melanoma patients: implications for the formulation of evidence-based follow-up guidelines. Ann Surg Oncol. 2007;14:1924-33.

8. Francken AB, Thompson JF, Bastiaannet E, Hoekstra HJ. [Detection of the first recurrence in patients with melanoma: three quarters by the patient, one quarter during outpatient follow-up]. Ned Tijdschr Geneeskd. 2008;152:557-62.

9. Hofmann U, Szedlak M, Rittgen W, Jung DG, Schadendorf D. Primary staging and follow-up in melanoma patients-monocenter evaluation of methods, costs and patient survival. $\mathrm{Br} J$ Cancer. 2002;87:151-7.

10. Mooney MM, Kulas M, McKinley B, Michalek AM, Kraybill WG. Impact on survival by method of recurrence detection in stage I and II cutaneous melanoma. Ann Surg Oncol. 1998;5:5463.

11. Shumate CR, Urist MM, Maddox WA. Melanoma recurrence surveillance. Patient or physician based? Ann Surg. 1995;221: $566-9$.

12. Garbe C, Paul A, Kohler-Spath H, Ellwanger U, Stroebel W, Schwarz M, et al. Prospective evaluation of a follow-up schedule in cutaneous melanoma patients: recommendations for an effective follow-up strategy. J Clin Oncol. 2003;21:520-9.

13. Weiss M, Loprinzi CL, Creagan ET, Dalton RJ, Novotny P, O'Fallon JR. Utility of follow-up tests for detecting recurrent disease in patients with malignant melanomas. JAMA. 1995;274: 1703-5.

14. Regan MW, Reid CD, Griffiths RW, Briggs JC. Malignant melanoma, evaluation of clinical follow up by questionnaire survey. Br J Plast Surg. 1985;38:11-4.

15. Poo-Hwu WJ, Ariyan S, Lamb L, Papac R, Zelterman D, Hu GL, et al. Follow-up recommendations for patients with American Joint Committee on Cancer Stages I-III malignant melanoma. Cancer. 1999;86:2252-8.

16. Moore DK, Zhou Q, Panageas KS, Brady MS, Jaques DP, Coit DG. Methods of detection of first recurrence in patients with stage I/II primary cutaneous melanoma after sentinel lymph node biopsy. Ann Surg Oncol. 2008;15:2206-14.

17. Kersey PA, Iscoe NA, Gapski JA, Osoba D, From L, DeBoer G, et al. The value of staging and serial follow-up investigations in patients with completely resected, primary, cutaneous malignant melanoma. Br J Surg. 1985;72:614-7.

18. Dicker TJ, Kavanagh GM, Herd RM, Ahmad T, McLaren KM, Chetty U, et al. A rational approach to melanoma follow-up in patients with primary cutaneous melanoma. Scottish Melanoma Group. Br J Dermatol. 1999;140:249-54.

19. Baughan CA, Hall VL, Leppard BJ, Perkins PJ. Follow-up in stage I cutaneous malignant melanoma: an audit. Clin Oncol ( $R$ Coll Radiol). 1993;5:174-80.

20. Basseres N, Grob JJ, Richard MA, Thirion X, Zarour H, Noe C, et al. Cost-effectiveness of surveillance of stage I melanoma. A retrospective appraisal based on a 10-year experience in a dermatology department in France. Dermatology. 1995;191:199203.

21. Moloney DM, Gordon DJ, Briggs JC, Rigby HS. Recurrence of thin melanoma: how effective is follow-up? Br J Plast Surg. 1996;49:409-13.

22. Kittler H, Weitzdorfer R, Pehamberger H, Wolff K, Binder M. Compliance with follow-up and prognosis among patients with thin melanomas. Eur J Cancer. 2001;37:1504-9.

23. Sylaidis P, Gordon D, Rigby H, Kenealy J. Follow-up requirements for thick cutaneous melanoma. Br J Plast Surg. 1997;50: 349-53.

24. Balch CM, Gershenwald JE, Soong SJ, Thompson JF, Atkins MB, Byrd DR, et al. Final version of 2009 AJCC melanoma staging and classification. J Clin Oncol. 2009;27:6199-206.

25. Bastiaannet E, Oyen WJ, Meijer S, Hoekstra OS, Wobbes T, Jager PL, et al. Impact of $[18 \mathrm{~F}]$ fluorodeoxyglucose positron emission tomography on surgical management of melanoma patients. Br J Surg. 2006;93:243-9.

26. Ariyan S, Poo WJ, Bolognia J, Buzaid A, Ariyan T. Multiple primary melanomas: data and significance. Plast Reconstr Surg. 1995;96:1384-9.

27. Brobeil A, Rapaport D, Wells K, Cruse CW, Glass F, Fenske N, et al. Multiple primary melanomas: implications for screening and follow-up programs for melanoma. Ann Surg Oncol. 1997;4: 19-23.

28. Johnson TM, Hamilton T, Lowe L. Multiple primary melanomas. J Am Acad Dermatol. 1998;39:422-7.

29. Austin PF, Cruse CW, Lyman G, Schroer K, Glass F, Reintgen DS. Age as a prognostic factor in the malignant melanoma population. Ann Surg Oncol. 1994;1:487-94.

30. Averbook BJ, Russo LJ, Mansour EG. A long-term analysis of 620 patients with malignant melanoma at a major referral center. Surgery. 1998;124:746-55.

31. Balch CM, Soong SJ, Bartolucci AA, Urist MM, Karakousis CP, Smith TJ, et al. Efficacy of an elective regional lymph node dissection of 1 to $4 \mathrm{~mm}$ thick melanomas for patients 60 years of age and younger. Ann Surg. 1996;224:255-63.

32. Cohen HJ, Cox E, Manton K, Woodbury M. Malignant melanoma in the elderly. J Clin Oncol. 1987;5:100-6.

33. Loggie B, Ronan SG, Bean J, Das Gupta TK. Invasive cutaneous melanoma in elderly patients. Arch Dermatol. 1991;127:1188-93.

34. Sahin S, Rao B, Kopf AW, Lee E, Rigel DS, Nossa R, et al. Predicting ten-year survival of patients with primary cutaneous melanoma: corroboration of a prognostic model. Cancer. 1997;80:1426-31.

35. Conway WC, Faries MB, Nicholl MB, Terando AM, Glass EC, Sim M, et al. Age-related lymphatic dysfunction in melanoma patients. Ann Surg Oncol. 2009;16:1548-52.

36. Francken AB, Hoekstra HJ. Follow-up of melanoma patients: the need for evidence-based protocols. Ann Surg Oncol. 2009;16: $804-5$.

37. http://dissertations.ub.rug.nl/FILES/faculties/medicine/2007/a.b. francken/melfo.pdf. 